\title{
An Integrated Framework for Immigrant Children and Youth's School Integration: A Focus on African Francophone Students in British Columbia - Canada
}

\author{
Mambo Tabu Masinda ${ }^{1, *}$, Marianne Jacquet ${ }^{2}$ \& Danièle Moore $^{2}$ \\ ${ }^{1}$ Burnaby School District, Canada \\ ${ }^{2}$ Faculty of Education, Simon Fraser University, Burnaby, Canada \\ *Corresponding author: E-mail: mambo_masinda@yahoo.ca
}

Received: September 23, 2013 Accepted: October 15, 2013 Published: February 28, 2014

doi:10.5296/ije.v6i1.4321ＵRL: http://dx.doi.org/10.5296/ije.v6i1.4321

\begin{abstract}
An abundant literature has been produced on immigrant children and youth education. However, few studies incorporate students' view in providing a comprehensive definition of immigrant children and youth's school integration. The aim of this paper is to provide an operational integrated guide, which may be useful for working with immigrant children and youth students, as it takes into consideration the social, cultural, psychological and academic dimensions of their school integration. This integrated guiding framework draws from a five-year experience of community-university partnership. The methodology consists of a review of the literature on the school integration of immigrant children and youth, comprehensive interviews with students, parents and community partners (previous publications by authors), and community's involvement through a consultation process to determine needs and priorities. The combined findings gathered from these sources are formulated into practical recommendations to assist educators in their support of immigrant children and youth' school integration process.
\end{abstract}

Keywords: immigrant children and youth; Francophone African immigrants; school integration 


\section{Introduction}

This integrated framework aims to provide guiding principles to those involved in promoting a better school integration for refugee and immigrant children and youth. It focuses on immigrant children and youth social, cultural, psychosocial and academic dimensions as critical factors for their successful school integration. Statistic Canada (2006) reported that most newcomers are now arriving from Asia and the Middle East (58.3\%), Europe (16.1\%), the Caribbean, Central and South America (10.8\%), and Africa (10.6\%). Interestingly, the number of immigrant children and youth has increased from 24\% in 1971 to 34\% in 2006. The National Household Survey (Statistics Canada, 2011) also indicates an increase in the number of immigrants from Africa between 2006 and 2011: they represented 12.5\% of the newcomers who arrived in Canada during that period, compared to the $10.3 \%$ who arrived during the previous five-year period.

The number of African immigrants in Canada continues to grow as the continent continues to be affected by political turmoil and wars. Indeed, at the end of 2010, Central Africa and the Great Lakes Region had 945,200 refugees, the East and Horn of Africa had 779,200 and the Southern Africa had 143,000, totaling 2,016,800 refugees from the Sub-Saharan Africa region (UNHCR, 2010). As a result, there have been a growing number of Sub-Saharan African Francophone immigrants arriving in British Columbia (BC), Canada. According to the Immigrant Services Society of BC (2010), British Columbia received 162 newcomers from the Democratic Republic of Congo, 51 from Togo, 44 from Burundi, 33 from Rwanda and 31 from the Republic of Congo between January 2005 and December 2009 (inclusive).

While this number may look relatively small, African sub-Saharan youth present specific characteristics and experiences, while they belong to communities still poorly known in Canada (Mondain, \& Lardoux, 2013). In British Columbia (BC), their situation is particularly complex: as an African Francophone Minority with diverse backgrounds, languages, cultures and previous school experiences, they have to overcome the challenge of having to transition into a Euro-North American Francophone Minority within a dominant English speaking society. Although they can choose to be schooled in English, our previous studies have shown that most African Francophone immigrant children and youth newly arrived in BC will attend Francophone schools designated for the Francophone community in minority situation, a right given by the 1982 Canadian Charter of Bills and Rights (Moore, Sabatier, Jacquet, \& Masinda, 2008; Jacquet, Moore, Masinda, \& Barankenguje, 2013).

In this paper, we use the term "Francophone" to describe individuals and groups whose cultural backgrounds are associated with the French language, for primarily historical reasons: as a legacy of the French and Belgian colonial empires for the newly arrived African minority groups in Canada; as a legacy of the French colonization of the American continent during the $17^{\text {th }}$ and $18^{\text {th }}$ centuries for the Canadian Francophones (and by extension, for the schools who provide for their instruction). Statistics Canada uses the term francophone to mean someone whose mother tongue is French and who still speaks French. This definition is too restrictive to describe Francophone Africans as French is not necessarily their primary language in the family sphere, but they come from a country where French is still an official 
language and the main language of instruction in schools and universities. Section 23 of the Canadian Charter of Rights and Freedoms makes it possible to be schooled in either English (for the Anglophone minority in Quebec), and French as a first language (Francophone schools) for Francophone minority outside Quebec. In this paper, we focus on youth and families who have chosen French-Education upon arrival in western (English-speaking) Canada. As such, they represent a minority within a minority context (Moore, Sabatier, Jacquet, \& Masinda, 2008).

The educational experience of Sub-Saharan African Francophone children and youth students attending Francophone schools in the Vancouver Metropolitan Region can be classified into 3 categories: 1) student with formal education, 2) student with no formal education and 3) student with interrupted education. Understanding their integration into the Canadian society is a multifaceted matter, as it involves a combination of complex factors, ranging from government policies, trajectory of migration, age, gender, length of stay, culture, socioeconomic status, pre and post-migration experience, as well as an understanding of the specific context in which their integration takes place. In this process, the school is considered to be a critical pillar in their academic learning, language, socio-cultural transition and emotional wellbeing.

Abundant literature has been produced regarding immigrant children and youth's school integration, but none has suggested an integrated framework, which encompasses the critical dimensions of school integration from the participants', and notably the youth's point of view. These include four interlinked key components: the social, cultural, psychological and academic factors. This integrated guide is born out of a five-year community-university partnership, which was initiated when educators within a Francophone School District (Conseil scolaire francophone - CSF) approached researchers from (Authors') University’s Faculty of Education to obtain greater insight on how educative practices could be tailored to better meet the needs of immigrant children and youth arriving from African Francophone countries (Jacquet, Moore, Masinda, \& Barankenguje, 2013; 2009; Moore, Sabatier, Jacquet, \& Masinda, 2008).

The contribution presents a review of the literature on school adjustment of immigrant children, as well as a synthesis of findings gathered from interviews and consultations conducted with students, parents and community workers. It moves on to provide a comprehensive framework that aims to offer guidance to enhance school integration, and as a basis for reflection and transformative action. This guiding document is the result of an inclusive and collaborative process to identify priorities of actions and set of goals. It contributes to provide a bottom up approach to intervention, and should encourage new ways of working together.

\section{Methodology}

While there are a growing number of studies examining refugee and immigrant children and youth's school integration, we lack an operational and integrated guiding framework to assist 
those working with refugee and immigrant children and youth to support and enhance their integration and engagement into Canadian schools. The methodology for the development of this framework was threefold: 1) gathering a mixed team of researchers to map the needs of Sub-Saharan Francophone immigrant children, their parents, and community partners through interviews, field notes and participant observations, 2) reviewing the literature pertaining to school adjustment, and 3) using the research findings as a basis for further consultation with the participants in order to collaboratively develop recommendations and provide directions for a common vision towards better school inclusion.

\subsection{Research Team Development}

From 2000, Francophone schools in BC started to receive an increasing number of African Francophone immigrant children and youth. Educators were struggling to cope with these changes because they lacked the appropriate professional training to effectively address the needs of this new student population. Accordingly, CSF teachers reached out to researchers at Authors University's Faculty of Education to seek for help. The first phase of the project began in 2005, with the objective to map the needs of the African Francophone immigrant children and youth in the CSF. Individual and group interviews were conducted with seven community participants engaged in facilitating immigrants' social integration to BC, seven parents, seven administrators and seven teachers from the CSF. In addition, an exploratory group interview with nine students was conducted in preparation for the second research phase. Based on the preliminary findings of this phase, three articles were published (Authors, 2010; Moore, Sabatier, Jacquet, \& Masinda, 2008; Jacquet, Moore, Sabatier, \& Masinda, 2008).

The second phase of the project began in 2009 aiming to expand on the needs of the African francophone children and youth in relation to their school integration identified in the first phase of the research. We conducted individual and group interviews with 64 participants (34 students, 18 parents, 9 community participants, and 3 school non-teaching professionals), as well as field observations during community led activities. The majority of the students and their parents are from the Democratic Republic of Congo (DRC), followed by Burundi, Rwanda, Togo and Madagascar. Most parents arrived in BC as refugees, and 10 parents out of 18 are from disadvantaged socioeconomic backgrounds. A large number of students (27) were attending high schools, and 7 were in elementary schools.

We expanded the research team to include three African Francophone immigrants hired as research assistants: one of them with over ten years of experience as a Francophone African immigrant, and as a community worker; one of them just newly arrived himself; and the third one a woman and mother, to work in close collaboration with women immigrants. With them were also hired young high school or first year university African students to conduct interviews and work with the younger students. Every member of the team was French-speaking, and all the research assistants could also speak various African languages on top of English.

The significant experience in teacher training of the faculty research team members, as well 
as the personal immigration experiences and community knowledge of the research assistants, contributed to the development of a dynamic and multilingual research team capable of providing different perspectives on various issues. The unique composition of the research team (mature, very young; male, female; African or not; all immigrants, multilinguals, and French-speaking) contributed to mitigating the risk of misunderstandings, and offered the possibility of multilayered interpretation of the data.

\subsection{Literature Review}

The literature review was grounded within the fields of expertise of the research team members, namely: the sociology and sociolinguistics of migration and education, the studies of ethnic relations in education and multicultural education in minority contexts, educational leadership, and language and education policy. Out of the results of the needs mapping of the African Francophone children and youth (Authors 2008; Authors, 2009), it became evident that the integrated framework we were seeking to develop needed a strong foundational support from the literature showing, for instance, the link between the critical role of peer relationships, student and teacher's perceptions, and the immigrant children and youth's social, cultural, psychological and academic transition. As the four dimensions of immigrant children and youth's school integration emerged through the literature review, a vision of those conditions necessary for successful school integration started to take place.

2.3 The research findings as a reflective tool for consultation with the participants to determine needs and priorities

To complete our understanding of key factors affecting school integration, we thought it vital to include students, parents and community workers' experiences and points of views. In fact, social, cultural, psychological and academic dimensions of immigrant children and youth school integration, is about their inclusion and participation, their own experiences of school, and how they view their relationships with their peers and teachers.

While the interviews and field observations provided key findings to understand challenges, needs and priorities, and provided a voice, notably for young immigrants and their families, a further process of consultation was necessary to determine a common vision for families, schools and community partners. We thus presented our findings to our community partners and the participants on several occasions, during workshops and community events organized by various French-speaking African community groups and associations: Café de l'intégration (monthly meetings to facilitate networking and integration of newly arrived francophone immigrants), church meetings, workshops during community-led events, and during a local professional conference where we presented a first draft of this framework to the community for their comments and feedback (some participants to this event had also been participants during various phases of our studies).

Thus, the study findings were used as a trigger for co-reflection on resources and needs. We used the participants' interview analyses as our guidelines to determine needs and priorities, engage community involvement, share experience, and discuss and co-develop the strategies that are presented in this framework. The literature review in the following section feeds on 
the themes that were then determined, and gives us further understanding to the issues at stake.

\section{Literature Review}

\subsection{The weight of the school environment}

The BC Ministry of Education (2009), in a document entitled Students from refugee backgrounds: A guide for teachers and schools recognizes that the school environment is critical to newcomer students' learning pertaining to social, cultural and emotional dimensions. Abundant literature on immigrant children and youth's school integration, examining macro factors, has demonstrated that large differences exist in the achievement scores of immigrant children and youth (European Commission, 2008), leading Schütz, \& Wößmann (2005, p. 15, cited in European Commission 2008) to this troubling question: what particular features of national education system can explain these differences?

If the outcomes of specific school on immigrant children and youth's school integration vary considerably across countries, despite policy similarities, then the school presents an interesting case for analysis. The question that emerges is: Are the school factors significant in explaining immigrant children and youth's school integration? Indeed, research in many countries has shown that the school plays an important role in helping immigrant children and youth to properly settle in schools, irrespective of individual factors, including self-determination, self-motivation, personality traits, parents' level of education, socio-cultural capital and self-coping mechanisms (Gump, 1980; Heckmann, 2008; Leithwood, Fullan \& Watson, 2003; Portes \& MacLeod, 1996 among others).

While schools are vital parts of the social systems they operate in, they are concurrently distinctive units embedded within cultural norms and practices that can either foster or hinder children and youth's school integration (Hudley, \& Daoud, 2008). In fact, it has been shown that where young people live and attend school largely determines their friendship formation and skills development (Crosnoe, 2000). In light of this evidence, schools must work to eliminate socially constructed boundaries that produce racial and cultural divides (Reitz, \& Banerjee, 2009).

\subsection{Barriers to immigrant children and youth's school integration}

Among the impediments to immigrant children and youth's school integration are language barriers, low expectations from teachers, poverty, racism, low levels of parental involvement and isolation combined with poor communication and cooperation among the school, parents, and community (Henderson \& Mapp, 2002). Most studies describe these students as challenging for educators, especially at the high school level, as they do not have enough time to develop language skills and social bonds in school.

Cultural distance may act to further impede students with limited or interrupted formal education, perhaps lacking the required Western social and cultural cues, to fully explore 
their potential (DeCapua, Smathers, \& Tang, 2007). In this sense, immigrant children and youth can be viewed as a unique segment among the many ethnically, religiously and culturally diverse immigrants arriving in great numbers. They display a unique and highly complex set of challenges that must be taken into account (Adutwum, 2009).

\subsection{Cultural dimension of school integration}

It has been argued that cultural factors need to be considered in the immigrant children and youth's school integration process (Hill \& Torres, 2010). Given that someone's culture is the vehicle through which he makes sense of the world and develops appropriate responses to the environment, it is not a leap to think that Francophone immigrant students perceive and analyze their daily school life experiences through the lens of their own respective cultures (Jacquet, Moore, Masinda, \& Barankenguje, 2013).

Cultural adjustment can be viewed as a negotiation process with the host culture. Its success depends on one's ability to effectively negotiate cultural distance in a host society (Ward, \& Kennedy, 1999). This acculturation process (Berry, 2003) and its impact in education has been discussed by many authors (Gonzalez, \& al., 2002; Suarez-Orozco, \& Suarez-Orozco, 2001; DeCapua, \& Marshall, 2010). Importantly, the school cultural integration is not a one-way process, it also requires that: (1) peer native students learn about newcomer student's cultures, and (2) schools develop policies and practices, fostering the inclusion of diversity in all dimensions of teaching through a strategy of combating subtractive schooling.

In this perspective, cultural integration is a co-constructed school culture transition since a unilateral construction would not be complete, given the meanings the child brings to the situation are of little value unless he can share with others (Fuller et al., 2010). While the BC Ministry of Education (2009) is seeking to foster the inclusion of diversity in all dimensions of students' school experience, teachers are consistently unaware neither of this framework, nor are they always aware of their responsibilities as educators and agents of socialization, or know how to respond to the unique challenges young African newcomers pose (Jacquet, 2009; Jacquet, Moore, Sabatier, \& Masinda, 2008). In sum, a successful integration is characterized by a promotion of strong cross-cultural identities: harmoniously combining the values and beliefs of both their home and school cultures.

\subsection{Social dimension of school integration}

Given the ability for positive relationships to create spaces for social, psychological and academic support, their importance to immigrant children and youth's school integration cannot be stressed enough. Indeed, studies have pointed to school sense of belonging as a vital feature in the school achievement of ethnic minority students (Kia-Keating, 2007). Research on ethnic minority students has also shown that perceived teacher attitudes and support are vital to keeping youth engaged in school (Hudley, \& Daoud, 2008).

Social integration is the degree to which an individual is connected to other individuals in a social setting. It refers to social skills or social competence and ability to interact adequately in the host society (Faulstich-Orellana, 2008). However, social integration may be 
challenging for newcomer students starving to develop a network of friends in their new schools, due to the complexity of learning to navigate a new land. In fostering immigrant children and youth's re-socialization process, schools act as agents of social integration because positive relationships serve as a vital foundation to learning new social codes, developing language skills, absorbing new cultural norms, and ensuring emotional support (Suarez-Orozco, Pimentel, \& Martin, 2009).

\subsection{Psychological dimension of school integration}

Focusing on immigrant children and youth's psychological wellbeing is of a great importance, as it has been reported that there is a close relationship between psychological wellbeing and academic success, peer relationships, positive identity and school bond and directly impact their behaviors and attitudes towards learning, teachers and peers (Salami, 2010).

\subsection{Academic dimension of school integration}

The academic dimension of school integration consists primarily of mastering understanding local teaching practices, being self-motivated, and continually investing in ones' learning process (Fredricks, Blumenfel, \& Paris, 2004). Upon arrival, newcomer students are rapidly exposed to different teaching and learning styles, perceptions of authority between teachers and students, and communication and participation styles. Collectively, these learning practices have an impact on their academic school integration process (Beacco, Chiss, Cicurel, \& Véronique, 2004). In the case of African youth, an additional challenge is that some of them do not have a previous school experience, because of war disruptions, persecution, deportation, and refugee resettlement (Moore, Sabatier, Jacquet, \& Masinda, 2008).

Research has shown that cultural differences affect achievement motivation (Kaplan, Karabenick, \& DeGroot, 2009). For instance, motivation has been found to be generated by culturally based factors such as classroom peer and teacher interactions (Hudley, \& Daoud, 2008). Accordingly, this strong relationship between learning motivation and culture is an element that necessitates consideration when dealing with immigrant students in their learning process.

For students who have undertaken formal schooling prior to arriving in Canada, their previous modes of instruction, as tools for learning and cultural transmission, may differ significantly from those common in Canada. The challenge this poses is particularly more acute for those who may have never received formal education, and instead may have acquired unique modes of learning to survive. Such a cultural mismatch with respect to modes of instruction effectively renders the school a cross-cultural learning experience. Accordingly, fostering awareness of this reality among educators can enable them to better identify, and subsequently better assist, immigrant students' adaptation to new modes of instruction (Trumbull, \& Rothstein-Fisch, 2011). 


\section{Summary of Findings: The Four Components for Success in the School Context}

It is not our ambition in this paper to present a detailed account of the findings from our research, as these have been discussed in details in previous publications. What we present here are key aspects of the complex issues immigrant children and youth and their families face as Francophone Africans in a minority French-speaking school environment within an Anglophone local context in British Columbia in Canada, from the participants' point of view. They illustrate the importance of four inter-related components towards successful integration into the school system for newcomers: the social and cultural components, the affective or psychological component, and the academic component.

In interviews conducted with African Francophone immigrant children and youth, immigrant students expressed feelings of being torn between home and host country cultures. At the same time, they expressed the desire to become bi-cultural individuals. Studies have demonstrated that the academic adjustment begins primarily with a general cultural transition as the newcomer student interacts with the new learning environment. This transition process can lead to affective, cognitive and behavior struggles (Gorgorio, Planas, \& Villela, 2002). Therefore, satisfaction with the learning environment is pivotal. According to newcomer students, coping with new teaching methods seem to be one of the toughest challenges in the integration process.

When asked about the support they receive from their teachers, most students reported that they had positive relationships with their Canadian teachers. While students expressed their appreciation for their teachers' hard work in caring for them, they expressed frustrations about teachers expecting them to quickly adapt to the Canadian learning style. For African Francophone immigrant students, the greatest barrier to their successful school integration was the lack of positive connections with school peers. However, they also indicated that in elementary schools, it was easier to have friends among Canadian born than in high schools where native students appear to be more resistant to establishing relations with immigrant students.

In certain instances, newcomer students' difficult relationships with peers contributed to a sense of frustration. The school was perceived as an unpleasant place to the point that some students recommended to their friends and family members to leave the Francophone school system. Community workers reported that, because the Francophone schools traditionally catered for a less diverse population of French-speaking students, they had not been as successful as mainstream English schools in designing, and implementing, welcoming programs in response to the increased number of Francophone immigrant students, notably from Africa.

It was additionally emphasized that the lack of specific integration services for immigrant children within the CSF was leading parents to withdraw their children from Francophone schools. Students also feared a perceived double standard with respect to school policies and procedures. For comparable mistakes, immigrant children believed they faced more severe penalties than their peers. Such perceived discriminatory treatment leaves newcomer students 
with a sense of injustice contributing to negative perceptions of adults and peers (for a detailed analysis of factors described as contributing to integration or exclusion, see Moore, Sabatier, Jacquet, \& Masinda (2008); Jacquet, Moore, \& Sabatier, 2008, 2009 and Jacquet, Moore, Masinda, \& Barankenguje, 2013).

While many other hardships were shared that could contribute to exclusion, sense of lost identity, and low achievement at school, the obstacles listed above were the ones that children and youth would emphasize as the most pervasive obstruction to success in their new situation. The following guiding principles and recommendations therefore focus on these four key components to suggest directions for comprehensive strategies to develop social inclusion for newcomers in Francophone schools in BC.

\section{Guiding Principles for Success for Children and Youth’s School Integration}

Based on the combined findings from the review of literature and our long-term partnership with the Conseil scolaire francophone and the communities and community partners, we would define immigrant children and youth's school integration as the healthy social, cultural, psychological and academic transitions that help immigrant children and youth to realize their full potential in the school. Its foundation lies in a collaborative development process, whereby immigrant students acquire social, cultural, psychological and academic know-how through their interactions with native peers and teachers. The integrated framework displayed below shows the four dimensions of the school integration as it was made apparent by the participants to our study, through their interviews, and later through further consultation. It therefore reflects their voices rather than ours.

The framework develops a comprehensive model for a better coordination of resources and actions. In other words, to promote and contribute to the better integration of children, youth and their families, all four dimensions for success in the school integration process need to be addressed: social, cultural, psychological and academic. For example, on the social dimension, the school should assess students' social needs during the registration, and orientation and welcoming. On the cultural dimension, an assessment and understanding of cultural differences among students has to be part of the menu. Activities of identifying psychological needs of students are highly important as well as their previous learning and teaching styles.

As the integration process focuses on the four dimensions, newcomer students close cultural distance and have better interactions with peers and develop a bi-cultural identity conducive to feeling secure and better perception of their interactions with pears and teachers. While the social, psychological and cultural dimensions are taken care of, newcomer students are better equipped for the academic dimension and fulfill their potential in school. 
INTEGRATED FRAMEWORK OF IMMIGRANT CHILDREN AND YOUTH'S SCHOOL INTEGRATION
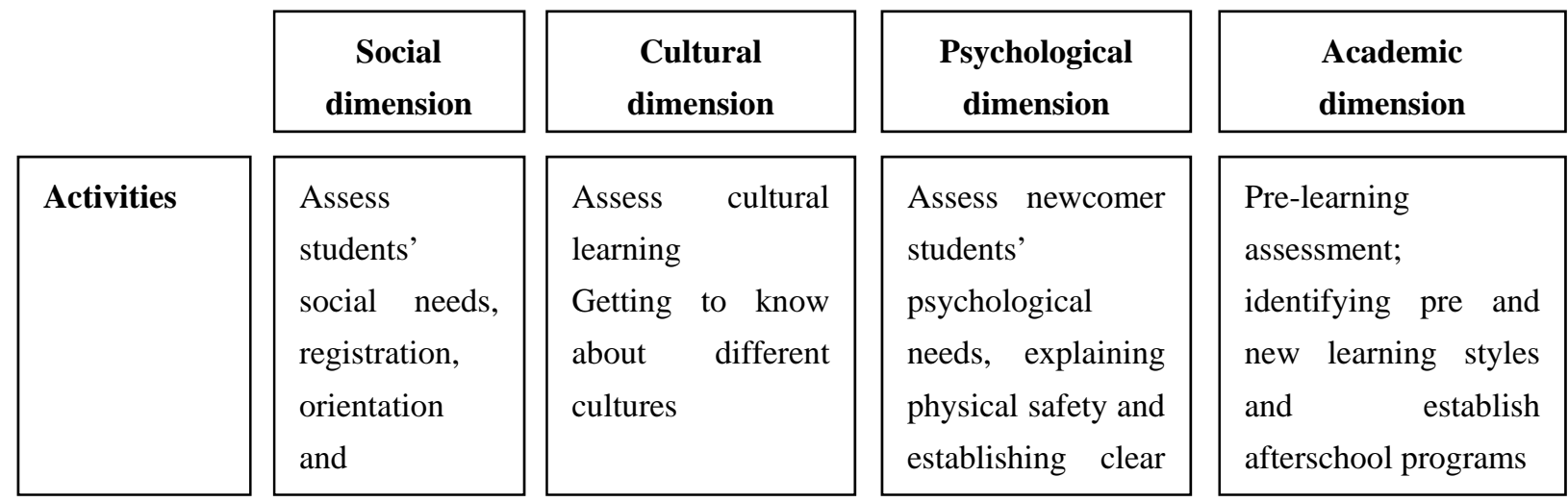

\begin{tabular}{|l|}
\hline Assess \\
students' \\
social needs, \\
registration, \\
orientation \\
and \\
\hline
\end{tabular}

\begin{tabular}{|l|}
\hline $\begin{array}{l}\text { Assess cultural } \\
\text { learning }\end{array}$ \\
Getting to know \\
about different \\
cultures
\end{tabular}

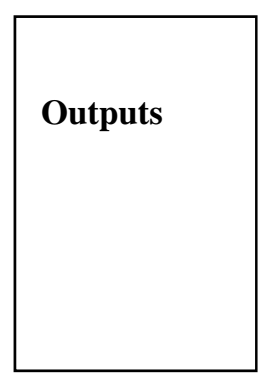

\begin{tabular}{|l|}
\hline Number of \\
assessed \\
students; more \\
students are \\
part of the \\
social \\
\hline
\end{tabular}

\begin{tabular}{|lr|}
\hline Cultural & distance \\
decreases; & \\
unwritten & cultural \\
codes & are \\
understood & and \\
practiced & \\
\hline
\end{tabular}

\begin{tabular}{|l|}
\hline Assess newcomer \\
students' \\
psychological \\
needs, explaining \\
physical safety and \\
establishing clear \\
\hline
\end{tabular}

Pre-learning assessment; identifying pre and new learning styles and establish afterschool programs

More newcomer students and native peers take part in the psychological wellbeing activities

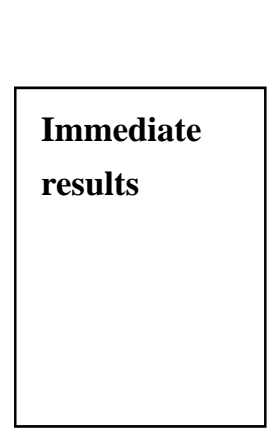

Newcomer
students and
peers
understand
each other,
positive
connectedness

\section{Intermediate results}

Newcomer
students have
a strong sense
of belonging
to the school

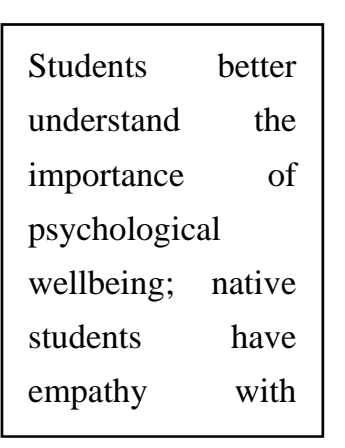

\section{Newcomer}

students develop a bi- cultural identity

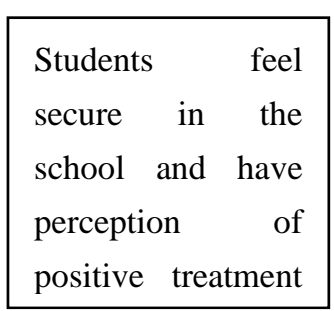

Newcomer students invest more in academic work; have great ability to cope with schooling

Better understanding of learning styles; better understanding of strengths and weaknesses

Immigrant children and youth students fulfill their social, cultural, psychological and academic potential in school 


\section{Recommendations as Best Strategies and Policy Implications}

As a result of the findings gathered from the literature review, our interviews with students, their parents and other community partners, and based on further consultations with the participants and community members, we suggest the following recommendations to guide school personnel and teacher-trainers' in their practices, as well as the development of school educational policies targeting immigrant children and youth.

\subsection{Recommendation \# 1: Be aware of the policy background and power of the school setting}

The school personnel need to understand the policy background that structures their role as educators, as well as reflect critically on the role of school practices in supporting immigrant children and youth's school integration. Thus, acknowledging the school's foundational role in fostering young newcomers' school integration contributes to the creation of a positive and reciprocal learning environment, where both students and teachers act as cultural brokers (Bartolomé, 2002).

\subsection{Recommendation \# 2: Create an educator-led integration team}

Teachers, as part of the school integration team, should collaboratively design educational strategies which spotlight the integration process of their students. These strategies should be periodically evaluated to ensure they are meeting expected outcomes. The collaborative approach to this process is designed to provide a sense of mutual respect and support among the students and school staff.

\subsection{Recommendation \# 3: Identify each child and youth needs and assets}

Assessing immigrant students' needs and assets is vital. In fact, the school must have a clear understanding of immigrant children and youth needs and assets as a foundational tool to work from. Moreover, comprehensive needs assessments enable teachers to better fulfill their role as educators by providing insights on the pressing needs of immigrant students, as well as the assets they bring to the school.

\subsection{Recommendation \# 4: Identify teachers' needs and assets}

Assessing the needs and assets of teachers is similarly vital, as it provides the opportunity to identify areas where professional development can be customized to assist educators in their support of newcomer integration. Professional development trainings should place a particular emphasis on the comprehensive nature of immigrant children students' school integration, which encompasses social, cultural, psychological and academic dimensions.

\subsection{Recommendation \# 5: Create school settings conducive to positive connectedness}

As social beings, positive relationships are vital to newcomer students' success in school. Positive relationships with peers are channels of emotional and academic support. They are the medium through which these students overcome their isolation. The key is to promote teachers' awareness of the importance of peer relationships, as well as native peers' understanding of their civic responsibility in supporting young newcomer students feel 
welcome in school.

\subsection{Recommendation \# 6: Strengthen teachers' and students' intercultural competence}

Intercultural understanding should be fostered through collective cross-cultural sharing among teachers, native and newcomer students. In this sense, teaching topics could consist of stories from diverse cultures designed to engage both students and teachers in a critical reflection on deep-seated stereotypes, prejudices, and cultural tensions. Such culturally grounded teaching and social activities are critical to preparing immigrant children and youth for a positive cultural transition. Culturally and linguistically appropriate services should be made readily available to immigrant students and their families.

\subsection{Recommendation \# 7: Ensure psychological support is readily accessible}

Acculturative tasks, which are highly demanding for immigrant children and youth, may result in anxiety, depression and feelings of discomfort. It is therefore imperative that the school designs activities and counseling services, which address immigrant children and youth's psychological wellbeing. This process may include 1) a general understanding of pre and post-migration stressors, 2) paying a particular attention to potential triggers of discomfort, and 3) taking into account students' unique personal experiences, such as passed traumatic events and discrimination. It is of additional importance that teachers, interacting directly on a daily basis with newcomer students and their families, undertake a reflection process to better assess the impact of their belief systems on these interactions (Exposito, \& Favela, 2003).

\subsection{Recommendation \# 8: Launch an academic transition plan for each student}

Reconciling Canadian and home cultures of learning practices should be at the centre of the support system for immigrant children students. Therefore, teachers must take into consideration the educational value systems of immigrant students, as well as their experience and knowledge repertoires when developing learning and socialization. Such an approach may help to avoid negative labeling of newcomer students.

\subsection{Recommendation \# 9: Improving teachers' academic preparation}

As noted by Jacquet (2009; 2007), Moore, Sabatier, Jacquet, \& Masinda (2008) and Walton, \& Escamilla (2002) teachers should be prepared to address the diverse social, cultural, linguistic and economic backgrounds of all students. For that reason, teacher-training curricula should focus on bumping up language development and diverse cultural assets to foster a positive schooling experience (Jacquet, Moore, Sabatier, \& Masinda, 2011). In examining their understanding of culture, identity and inclusion in multiethnic schools, teachers are provided the opportunity to reflect critically on their educational practices towards students from diverse socio-cultural backgrounds. This introspective process, in combination with intercultural dialogue, is conducive to the development of more inclusive school practices (Jacquet, Moore, Sabatier, \& Masinda, 2011). 


\section{Conclusion}

The guiding principles presented in this integrated framework are anchored in a literature review of school integration, key findings drawn from a five-year research experience with Francophone schools in the province of British Columbia, and various consultations with the participants to the study and community partners. The framework suggests a definition of immigrant children's school integration, and presents an integrated framework encompassing social, cultural, psychological and academic dimensions of school integration, as voiced by African participants and community partners.

It becomes clear that immigrant children and youth's school integration is a transitional process through which they construct new identities, integrating home and host country practices. Francophone immigrant students growing up in a minority situation are in need of culturally anchored interventions, which support their integration process. Schools could benefit from a coordinated and strength-based approach looking at potential assets young newcomers bring to the school. Such an approach is a form of student-centered care, demonstrating a commitment to providing equitable services for all.

The findings recommend that schools should pay attention to the social, cultural, psychological and academic dimensions of newcomer students' school integration process. To foster a smooth transition, schools must establish proactive educator-led integration teams to better support immigrant students. Educators should critically reflect on how their attitudes may influence their teaching practices and their interactions with newcomer students.

Such a reflection process, engendering a greater understanding of their personal strengths and needs, would additionally enable educators to better benefit from an intercultural professional training. The unique contribution of this framework is that it provides a common vision for schools, families and community partners, and helps approach the school integration process through an integrative and multi-dimension perspective. It is designed to engage educators to embrace reflective perspective on the diverse paths, aspirations, and strengths of immigrant children and youth in school.

\section{Acknowledgments}

This two-phases research was supported by a standard grant from the Social Sciences and Humanities Research Council of Canada (Jacquet, Moore, \& Sabatier, 2009-2012), and a grant from the Research Center on Immigration and Integration in the Metropolis (Jacquet, Sabatier \& Moore, 2005-2007). We would like as well to thank our research participants: the African youths, their parents, the community workers, as well as teachers and school administrators from the Francophone School District, who have generously accepted to share with us their experience and knowledge of African students’ school integration. 


\section{References}

Adutwum, Y. O. (2009). The impact of culture on academic achievement among Ghanaian immigrant children. Unpublished Doctoral thesis, Faculty of the graduate school University of Southern California. Retrieved from http://digitallibrary.usc.edu/assetserver/controller/item/etd-Adutwum-2916.pdf

Bartolomé, L. (2002). Creating an equal playing field: Teachers as advocates, border crossers, and cultural brokers. In Z.F. Beykont (Ed.). The power of culture: Teaching across language difference (pp. 167-191). Cambridge, MA: Harvard Education Publishing Group.

BC Ministry of Education (2009). Diversity in BC Schools: A Framework. Retrieved from http://www.bced.gov.bc.ca/diversity/diversity_framework.pdf

Beacco, J. C., Chiss, J. L., Cicurel, F., \& Veronique, D. (Eds) (2005). Les cultures éducatives et linguistiques dans l'enseignement des langues. Paris: Presses Universitaires de France.

Berry, J. W. (2003). Conceptual approaches to acculturation. In Kievin M., Chun, Pamela Balls Organista et G. Marín, (eds.), Acculturation: Advances in theory, measurement, and applied research. Washington, DC, US: American Psychological Association, 17-37.

Crosnoe, R., Cavanaugh, S., \& Elder, G. (2003). Adolescent friendships as academic resources: The intersection of friendship, race, and school disadvantage. Sociological Perspectives, 46(3), 331-352. http://dx.doi.org/10.1525/sop.2003.46.3.331

Decapua, A., \& Marshall, H. W. (2010). Serving ELLs With Limited or Interrupted Education: Intervention That Works. Retrieved from http://www.tesolmedia.com/docs/TJ/firstissue/06_TJ_DeCapuaMarshall.pdf

DeCapua, A., Smathers, W., \& Tang, F. (2007). Addressing the challenges and needs of students with interrupted formal education (SIFE). Educational Policy and Leadership, 65, 40-46.

European Commission (2008). Education and migration strategies for integrating migrant children in European schools and societies. Retrieved from http://www.nesse.fr/nesse/activities/reports/activities/reports/education-and-migration-p df

Exposito, S., \& Favela, A. (2003). Reflective voices: Valuing immigrant students and teaching with ideological clarity. The Urban Review, 35(1), 73-91. http://dx.doi.org/10.1023/A:1022597607497

Faulstich-Orellana, M. (2008). Translating childhoods: immigrant youth, language, and culture. Candem: NJ Rutgers University Press.

Fredricks, J. A., Blumenfeld, P. C., \& Paris, A. H. (2004). School engagement: Potential of 
the concept, state of the evidence. Review of Educational Research, 74(1), 59-109. http://dx.doi.org/10.3102/00346543074001059

Fuller, B., \& Coll, C. G. (2010). Learning from Latinos: Contexts, families, and child development in motion. Developmental Psychology, 46(3), 559-565. http://dx.doi.org/10.1037/a0019412

Gonzales, A., Knight, G. P., Morgan-Lopez, A., Saenz, D., \& Sirolli, A. (2002). Acculturation and the mental health of Latino youth: An integration and critique of the literature. In J. Contreras, A. Neal-Barnett, \& K. Kerns (Eds.), Latino children and families in the United States: Current research and future directions (pp. 45-74). Westport, CT: Praeger.

Gorgorió, N., Planas, N., \& Vilella, X. (2002). Immigrant children learning mathematics in mainstream schools. In Abreu, G, Bishop, A. J. \& Presmeg, N. (Eds.). Transitions between contexts of mathematical practices (pp. 23-52). Dordrecht: Kluwer. http://dx.doi.org/10.1007/0-306-47674-6_3

Gump, P. V. (1980). The school as a social situation. Annual Review of Psychology, 31, 553-582. http://dx.doi.org/10.1146/annurev.ps.31.020180.003005

Heckmann, U. (2008). Education and Migration. Strategies for integrating migrant children in European schools and societies. A synthetis of research findings for policy-makers. NESSE: European Commission.

Hill, N. E., \& Torres (2010). Negotiating the American dream: The paradox of aspirations and achievement among Latino students and engagement between their families and schools. Journal of Social Issues, 66(1), 95-112. http://dx.doi.org/10.1111/j.1540-4560.2009.01635.x

Hudley, C., \& Daoud, A. M. (2008). Cultures in contrast: Understanding the influence of school culture on student engagement. In C. Hudley \& A. E. Gottfried (Eds.), Academic motivation and the culture of school in childhood and adolescence (pp. 187-215). New York, NY: Oxford University Press. http://dx.doi.org/10.1093/acprof:oso/9780195326819.003.0009

Immigrant Services Society of British Columbia. (2010). Changing faces, changing neighborhoods: Government assisted refugee settlement patterns in Metro Vancouver January $2005 \quad$ - $\quad$ December 2009. Retrieved from http://issbc.org/system/cms/files/131/files/original/ChangingFaces-GARpublication.pdf

Jacquet, M. (2007). La formation des maîtres à la pluriethnicité : pédagogie critique, silence et désespoir. Revue des Sciences de l'éducation, 33(1), 25-45. http://dx.doi.org/10.7202/016187ar

Jacquet, M. (2009). L'espace marginal de l'inclusion de la diversité ethnique à l'école : l'exemple de la Colombie-Britannique. Canadian Ethnic Studies, 41(1-2), 95-113. http://dx.doi.org/10.1353/ces.2009.0009 
Jacquet, M., Moore, D., \& Sabatier, C. (2008). Médiateurs culturels et insertion de nouveaux arrivants francophones africains : parcours de migration et perception des rôles. Revue Glottopol, 11, January, Insertion scolaire et insertion sociale des nouveaux arrivants, 81-94. Retrieved from http://glottopol.univ-rouen.fr/telecharger/numero_11/gpl11_08jacquet.pdf

Jacquet, M., Moore, D., Masinda, M. T., \& Barankenguje, J. (2013). Claiming the Voice of Hope: The School Integration of Sub-Saharan African French-Speaking Children and Youth Immigrants in British Columbia, Canada. In I. Harushimana, C. Ikpeze, \& S. Mthethwa-Sommers (Eds.). Reprocessing Race, Language and Ability: African-Born Students and Educators in Transnational America (pp. 135-149). New York, NY: Peter Lang.

Jacquet, M., Moore, D., Sabatier, C., \& Masinda, M. T. (2011). Aider à l'intégration des jeunes immigrants francophones africains dans les écoles francophones à Vancouver en Colombie-Britannique. Nos Diverses Cités 8, printemps, 64-69.

Kaplan, A., Karabenick, S., \& De Groot, E. (2009). Introduction: Culture, self, and motivation: The contribution of Martin L. Maehr to the fields of achievement motivation and educational psychology. In A. Kaplan, S. Karabenick, \& E. De Groot (Eds.), Culture, self, and motivation: Essays in honor of Martin L. Maehr (pp. vii-xxi). Charlotte, NC: Information Age Publishing.

Kia-Keating, M. (2007). Belonging in connection to school in resettlement: Young refugees, school belonging, and psychosocial adjustment. Clinical Child Psychology and Psychiatry, 12(1), 29-43. http://dx.doi.org/10.1177/1359104507071052

Leithwood, K., Fullan, M., \& Watson, N. (2003). The Schools We Need: Recent Education Policy in Ontario. Recommendations for Moving Forward. Toronto: University of Toronto (OISE).

Mondain, N., \& Lardoux, S. (2013). Transitions to adulthood among first generation Sub-Saharan African immigrant adolescent in Canada. Migration and Integration, 14, 307-326.

Moore, D., Sabatier, C., Jacquet, M., \& Masinda, M. T. (2008). Voix africaines à l'école de la francophonie canadienne. Réflexions pour une culture didactique du plurilinguisme contextualisée. In P., Blanchet, D., Moore, S., Asselah-Rahal (Eds.), Perspectives pour une didactique des langues contextualisée (pp. 19-40). Collection Savoirs francophones, Éditions des Archives Contemporaines et Agence Universitaire de la Francophonie.

Portes, A., \& Dag MacLeod, D. (1996). Educational progress of children of immigrants: The roles of class, ethnicity and school context. Sociology of Education, 69(4), 255-275. http://dx.doi.org/10.2307/2112714

Reitz, J. G., \& Banerjee, R. (2009). Racial inequality and social integration. In J. R., Reitz, R. Breton \& K. Dion (Eds.), Multiculturalism and social cohesion: Potentials and 
challenges of diversity, (pp. 123-55). New York: Springer.

Salami, S. O. (2010). Emotional intelligence, self-efficacy, psychological well-being and students' attitudes: Implications for quality education. European Journal of Educational Studies, 2(3), 247-257.

Statistics Canada. (2007). Census 2006: The evolving linguistic portrait, 2006 Census: Findings. $\quad$ Retrieved from http://www12.statcan.ca/census-recensement/2006/as-sa/97-555/index-eng.cfm

Statistics Canada. (2011). The national household survey (NSH): Immigration and ethnocultural diversity in Canada. Retrieved from http://www12.statcan.gc.ca/nhs-enm/2011/as-sa/99-010-x/99-010-x2011001-eng.cfm

Suarez-Orozco, C., \& Suarez-Orozco, M. (2001). Children of immigration. Cambridge, MA: Harvard University Press.

Suárez-Orozco, C., Pimentel, A., \& Martin, M. (2009). The significance of relationships: Academic engagement and achievement among newcomer immigrant youth. Teachers College Record, 111(3), 71-749.

Trumbull, E., \& Rothstein-Fisch, C. (2011). The Intersection of culture and achievement motivation. The School Community Journal, 21(2), 25-53.

UNHCR (2010). Global Trends 2010. Retrieved from http://www.unhcr.org/4dfa11499.html

Walton, P., Baca, L., \& Escamilla, K. (2002). A national study of teacher education: Preparation for diverse student populations. Center for Research on Education, Diversity, and Excellence (CREDE). Retrieved from http://www.crede.ucsc.edu/

Ward, C., \& Kennedy, A. (1999). The measurement of sociocultural adaptation. International $\begin{array}{llll}\text { Journal of Intercultural } & \text { Relations, }\end{array}$ http://dx.doi.org/10.1016/S0147-1767(99)00014-0

\section{Copyright Disclaimer}

Copyright reserved by the author(s).

This article is an open-access article distributed under the terms and conditions of the Creative Commons Attribution license (http://creativecommons.org/licenses/by/3.0/). 